\title{
Effect of Sulfonylurea Agents on Reverse Cholesterol Transport in Vitro and Vivo
}

\author{
Yoshio Terao ${ }^{1,2}$, Makoto Ayaori ${ }^{1}$, Masatsune Ogura ${ }^{1}$, Emi Yakushiji ${ }^{1}$, Harumi Uto-Kondo ${ }^{1}$, Tetsuya Hisada ${ }^{3}$, \\ Hideki Ozasa ${ }^{1,2}$, Shunichi Takiguchi ${ }^{1}$, Kazuhiro Nakaya ${ }^{1}$, Makoto Sasaki ${ }^{1}$, Tomohiro Komatsu ${ }^{1}$, \\ Maki lizuka1, Shunpei Horii ${ }^{1}$, Seibu Mochizuki ${ }^{4}$, Michihiro Yoshimura², and Katsunori Ikewaki ${ }^{1}$ \\ ${ }^{1}$ Division of Anti-aging, Department of Internal Medicine, National Defense Medical College, Saitama, Japan \\ ${ }^{2}$ Division of Cardiology, Department of Internal Medicine, The Jikei University School of Medicine, Tokyo, Japan \\ ${ }^{3}$ Department of Public Health and Hygiene, National Defense Medical College, Saitama, Japan \\ ${ }^{4}$ Musashino University Medical Center, Tokyo, Japan
}

\begin{abstract}
Aim: Reverse cholesterol transport (RCT) is a critical mechanism for the anti-atherogenic property of HDL. The inhibitory effect of the sulfonylurea agent (SUA) glibenclamide on ATP binding-cassette transporter (ABC) A1 may decrease HDL function but it remains unclear whether it attenuates RCT in vivo. We therefore investigated how the SUAs glibenclamide and glimepiride affected the functionality of ABCA1/ABCG1 and scavenger receptor class B type I (SR-BI) expression in macrophages in vitro and overall RCT in vivo.

Methods: RAW264.7, HEK293 and BHK-21 cells were used for in vitro studies. To investigate RCT in vivo, 3H-cholesterol-labeled and acetyl LDL-loaded RAW264.7 cells were injected into mice.

Results: High dose $(500 \mu \mathrm{M})$ of glibenclamide inhibited ABCA1 function and apolipoprotein A-I (apoAI)-mediated cholesterol efflux, and attenuated ABCA1 expression. Although glimepiride maintained apoA-I-mediated cholesterol efflux from RAW264.7 cells, like glibenclamide, it inhibited ABCA1-mediated cholesterol efflux from transfected HEK293 cells. Similarly, the SUAs inhibited SR-BI-mediated cholesterol efflux from transfected BHK-21 cells. High doses of SUAs increased ABCG1 expression in RAW264.7 cells, promoting HDL-mediated cholesterol efflux in an ABCG1-independent manner. Low doses (0.1-100 $\mu \mathrm{M})$ of SUAs did not affect cholesterol efflux from macrophages despite dose-dependent increases in ABCA1/G1 expression. Furthermore, they did not change RCT or plasma lipid levels in mice. Conclusion: High doses of SUAs inhibited the functionality of ABCA1/SR-BI, but not ABCG1. At lower doses, they had no unfavorable effects on cholesterol efflux or overall RCT in vivo. These results indicate that SUAs do not have adverse effects on atherosclerosis contrary to previous findings for glibenclamide.
\end{abstract}

J Atheroscler Thromb, 2011; 18:513-530.

Key words; Sulfonylurea, Macrophage, Cholesterol efflux, RCT

\section{Introduction}

High density lipoprotein (HDL) removes cholesterol pathologically accumulated in atherosclerotic lesions and transports it back to the liver for subsequent

Address for correspondence: Makoto Ayaori, Division of Anti-aging, Department of Internal Medicine, National Defense Medical College, 3-2 Namiki, Tokorozawa, Saitama, 359-8513, Japan

E-mail: ayaori@ndmc.ac.jp

Received: November 6, 2010

Accepted for publication: April 7, 2011 conversion to bile, and then into feces in a process called reverse cholesterol transport $(\mathrm{RCT})^{1)}$. Cholesterol efflux is the initial step in RCT and plays a pivotal role in maintaining intracellular cholesterol levels, thereby preventing the formation of macrophage-derived foam cells in atherosclerotic plaques. ATP binding cassette transporter A1 (ABCA1) has been shown to play an important role in apolipoprotein A-I (apoAI)-mediated cholesterol efflux from peripheral cells and macrophages ${ }^{2,3)}$. Further, ATP binding cassette transporter G1 (ABCG1) and scavenger receptor class $B$ type I (SR-BI) promote cholesterol efflux from mac- 
rophages to HDL particles but not to lipid-poor apoA- $\mathrm{I}^{4,5)}$, and thus work in concert to facilitate the cholesterol efflux reaction through a wide range of HDL subspecies.

Type 2 diabetes is an important risk factor for the development of cardiovascular diseases $(\mathrm{CVD})^{6}$ ) and recently, blood glucose level management has been shown to be important in avoiding microvascular and macrovascular complication of diabetes ${ }^{7,8)}$. Oral anti-diabetic sulfonylurea agents (SUAs) have been widely used to improve glycemic control. Although insulin resistance is a primary metabolic defect underlying glucose intolerance in Caucasian populations, impaired insulin secretion is the primary cause of glucose intolerance in the Japanese population, making SUAs first-line drugs in Japan; however, despite their glucose-lowering property, it has been controversial whether SUAs reduce CVD events ${ }^{9}$.

SUR1 and SUR2, receptors for sulfonylurea (SUR), are members of the ATP-binding cassette (ABC) transporter family, causing concern that SUAs could theoretically have an adverse effect on other ABC family members, including ABCA1/G1. Indeed, in the experimental setting, glibenclamide, a second generation SUA, has been shown to inhibit ABCA1and SR-BI- mediated cholesterol efflux at unphysiologically high concentrations ${ }^{2,10-14)}$. Therefore, there has been concern that its beneficial glucose-lowering effect could be offset by attenuated cholesterol efflux from macrophages in atherosclerotic plaques, resulting in increased CVD events. Moreover, it remains unclear whether glimepiride, another SUA, exerts a similar effect in vitro and if this unfavorable property translates into decreased overall RCT in vivo.

We undertook this study in order to investigate: 1) the effects of the two SUAs at therapeutic to superphysiologically high concentrations on cholesterol efflux and ABCA1/G1 and SRBI expressions in vitro, 2) underlying molecular mechanisms of the effects of high-dose SUAs and 3) effects of SUAs at therapeutic concentrations on overall RCT in mice in vivo.

\section{Methods}

\section{Materials}

Glibenclamide, N6,2'-O-dibutyryladenosine 3',5'-cyclic monophosphate sodium salt (db-cAMP), and human apoA-I were purchased from Sigma (St. Louis, MO). Glimepiride was donated by Sanofi Aventis (Tokyo, Japan). HDL was isolated by sequential ultracentrifugation and acetylated LDL (acLDL) was prepared according to the methods previously reported $^{15,16)}$.

\section{Cell Cultures}

RAW264.7, COS-7, HEK293, and BHK-21 (Riken Cell Bank, Tsukuba, Japan) cells were maintained in Dulbecco's modified Eagle's medium (DMEM) containing 10\% fetal bovine serum (FBS). THP-1 cells (Riken Cell Bank) were maintained in RPMI 1640 (Sigma) containing 10\% FBS. The differentiation of THP-1 monocytes into macrophages was induced in the presence of $320 \mathrm{nmol} / \mathrm{L}$ PMA for 72 hours. Cells were cultured in a humidified atmosphere at $37^{\circ} \mathrm{C}$ with $5 \% \mathrm{CO}_{2}$.

\section{Concentrations of SUAs for In Vitro Experiments}

Previous in vitro studies used glibenclamide at concentrations ranging from $100 \mu \mathrm{M}$ to $1 \mathrm{mM}$ as an inhibitor of SR-BI- and apoA-I-mediated cholesterol efflux $^{2,12,14,17)}$. On the other hand, when SUAs were orally administered to humans in clinical practice, the Cmax of glimepiride and glibenclamide was $0.1 \mu \mathrm{M}$ and $0.17 \mu \mathrm{M}$ at clinical doses (1 mg, $2.5 \mathrm{mg} /$ body), respectively. Based on these data, for in vitro experiments, we used concentrations ranging from 0.1 to $500 \mu \mathrm{M}$, which correspond to therapeutic to superphysiological concentrations, respectively.

\section{Determination of Cholesterol Efflux}

Cholesterol efflux experiments were performed as previously described ${ }^{15,16}$. RAW264.7 cells or THP-1 macrophages were labeled with ${ }^{3} \mathrm{H}$-cholesterol $(1.0 \mu \mathrm{Ci} /$ $\mathrm{mL}$ ) in media containing $0.2 \%$ bovine serum albumin (BSA) for $24 \mathrm{~h}$, in the presence of $0.3 \mathrm{mmol} / \mathrm{L} \mathrm{db}$ cAMP for RAW264.7 cells. The cells were washed twice with phosphate-buffered saline (PBS) and incubated for $24 \mathrm{~h}$ in DMEM containing $0.2 \%$ BSA in the presence or absence of glimepiride or glibenclamide. The media were replaced with DMEM containing $0.2 \% \mathrm{BSA}$ and incubated in the presence or absence of apoA-I $(10 \mu \mathrm{g} / \mathrm{mL})$ or HDL $(50 \mu \mathrm{g} / \mathrm{mL})$ for $24 \mathrm{~h}$. The percentage cholesterol efflux was calculated by dividing the media-derived radioactivity by the sum of the radioactivity in the media and the cells.

\section{Western Blot Analyses}

Cells were harvested and protein extracts prepared as previously described ${ }^{15,16)}$. Plasma membrane (PM) fraction was isolated using the Mem-PER kit (Pierce, Rockford, IL) according to the manufacturer's instructions. They were then subjected to Western blot analyses (10\% SDS-PAGE; $25 \mu \mathrm{g}$ protein per lane) using rat anti-ABCA1 antiserum (kindly donated by Dr. S. Yokoyama of Nagoya City University) ${ }^{18)}$, and rabbit anti-ABCG1, anti-SR-BI (Novus Biologicals, Littleton, CO), anti-LDL receptor (LDL-R) (Ab- 
cam, Cambridge, MA), and $\beta$-actin-specific antibodies (Santa Cruz Biotechnology, Santa Cruz, CA). The proteins were visualized and quantified using a chemiluminescence method (ECL Plus Western Blotting Detection System; GE Healthcare UK Ltd) and the NIH image analysis software program. Results are representative of 3 or more experiments.

\section{Real-time Quantitative RT-PCR}

At the indicated hours after treatment with glibenclamide or glimepiride, total RNA was extracted from the cells, and first-strand cDNA was synthesized from the total RNA (500 ng) by placing in a Reverse Transcription Reagent (Applied Biosystems, Foster City, CA). Quantitative PCR was performed with Perkin-Elmer 7900 PCR equipment, TaqMan PCR master mix and FAM-labeled TaqMan probes (Assays-onDemand; Applied Biosystems) for human or mouse ABCA1, ABCG1, SR-BI and glyceraldehyde-3-phosphate dehydrogenase (GAPDH). Expression data were normalized for GAPDH levels.

\section{Construction of Expression Plasmids Encoding ABCA1, ABCG1 and SR-BI}

To obtain open reading frames of human ABCA1 (hABCA1), hABCG1 and hSR-BI, RT-PCR was performed using first-strand cDNA derived from human monocyte-derived or mouse peritoneal macrophages as a template and the specific primers. To generate expression vectors for hABCA1, hABCG1 and hSR-BI, PCR products with or without FLAG epitope sequences in the carboxyl terminus were ligated in NotI sites of pcDNA3.1 (+) (Invitrogen, Carlsbad, CA), designated as phABCA1 (-FLAG), phABCG1 (-FLAG) and phSR-BI, respectively. The sequences of primers with NotI sites used for vector construction were as follows: phABCA1 forward: 5'-GCG GCC GCC ACC ATG GCT TGT TGG CCT CAG CT-3'; phABCA1-FLAG reverse: 5'-GCG GCC GCT CAC TTG TCG TCA TCG TCT TTG TAG TCC CAT ACA TAG CTT TCT TTC ACT TTC TCA-3'; phABCG1 forward: 5'-GCG GCC GCC ACC ATG GCC GCT TTC TCG GTC G-3’; phABCG1-FLAG reverse: 5'-GCG GCC GCT CAC TTG TCG TCA TCG TCT TTG TAG TCC CTC TCT GCC CGG ATT TTG T-3'

phABCA1 reverse: 5'- TCA TAC ATA GCT TTC TTT CAC-3' ;phABCG1 reverse: 5'-GCG GCC GCT TAC CTC TCT GCC CGG ATT TTG T-3'; phSR-BI forward: 5'-GCG GCC GCC ACC ATG GGC TGC TCC GCC CAA GC-3'; phSR-BI reverse: 5'-GCG GCC GCC TAC AGT TTT GCT TCC TGC AGC AC-3'. All constructs were verified by DNA sequencing.

\section{Transient transfection with phABCA1 in HEK293 cells}

HEK293 cells were seeded into 6- or 12- well plates. At 50-60\% confluence, cells were transiently transfected with a plasmid construct expressing human ABCA1, or an empty vector (mock) using Lipofectamine LTX reagent (Invitrogen) according to the manufacturer's instructions. After $48 \mathrm{~h}$ of infection, the medium was replaced with DMEM containing with $0.2 \%$ BSA and cells were used for cholesterol efflux assays or Western blot analyses.

\section{Generation of stable cell lines expressing human SR-BI}

To generate hSR-BI-expressing cells, BHK-21 cells were transfected with phSR-BI using Lipofectamine LTX reagent (Invitrogen). Stable cell clones were selected in DMEM supplemented with FBS $(10 \% \mathrm{v} / \mathrm{v})$ and $\mathrm{G} 418$ sulfate $(0.8 \mathrm{mg} / \mathrm{ml}$; Invitrogen $)$. In control cells transfected with the parental vector pcDNA3.1 (+), no expression of SR-BI was detectable at the protein level as determined in specific immunoblots, as described above.

\section{Cloning and Generation of Recombinant Adenoviruses Encoding for Human ABCG1}

Recombinant adenovirus expressing hABCG1 (Ad-hABCG1) was produced using the ViraPower Adenoviral Expression System (Invitrogen), according to the manufacturer's instructions. Briefly, to generate an entry clone of the Gateway system (Invitrogen), cloning of the open reading frame into a pENTR/ $\mathrm{D}$-TOPO vector (Invitrogen) was carried out using phABCG1 as a template and the specific primers as follows: forward: 5'-CAC CAT GGC CGC TTT CTC GGT CG-3'; reverse: 5'-TTA CCT CTC TGC CCG GAT TTT GT-3’.

An expression clone for adenoviral vector was then generated by performing an LR recombination reaction between the entry clone and a $\mathrm{pAd} / \mathrm{CMV} / \mathrm{V} 5$ DEST (Invitrogen) according to the manufacturer's protocol. The recombinant adenoviral plasmid was purified and then transfected into 293A cells. After a sufficient cytopathic effect was observed in 293A cells, the adenovirus was purified using the Adeno-X Virus Purification Kit (Clontech, Palo Alto, CA, USA). Adenoviral vector expressing luciferase (Ad-Luc) was kindly donated by Dr. Santamarina-Fojo of the $\mathrm{Na}$ tional Institute of Health ${ }^{19)}$, and used as a control. The adenovirus titer in plaque-forming units was determined by a plaque formation assay following infec- 
tion of HEK293 cells. The multiplicity of infection (MOI) was defined as the ratio of the total number of plaque-forming units to the total number of cells that were infected.

\section{Cloning and Generation of Recombinant Adenoviruses Encoding for Synthetic microRNAs Targeting Mouse ABCG1}

The pre-microRNA (miRNA) sequences for mouse ABCG1 were designed using an RNAi designer on-line tool, Invitrogen's RNAi Designer ${ }^{20)}$. Three different double-stranded oligo duplexes encoding desired miRNA target sequences were selected and cloned into pcDNA6.2/EmGFP-GW vector (Invitrogen). The sequences of one of the most efficient oligo duplexes are as follows: top sequence 5'- TGC TGT ATC CTT TCT TCT TCC ACC AGG TTT TGG CCA CTG ACT GAC CTG GTG GAA AGA AAG GAT A -3' and bottom sequence 5'- CCT GTA TCC TTT CTT TCC ACC AGG TCA GTC AGT GGC CAA AAC CTG TGG AGA GAA GGA AC -3'. The sequences of the negative control oligo duplex are as follows: top sequence 5'-GCT AAA GTA TGC CGT GAG CGT TTG CCA TGA TGA GTC CCA GCA TAC TTT-3' and bottom sequence 5'-CCT AAA GTA TGC TGG GAC TCA TCA TGG CAA ACG CTC CGC CAG ACA TTC-3'. The miR flanking sequence was transferred into pDONR221 vector (Invitrogen) to generate an entry vector, which was used to generate adenoviruses encoding synthetic miRNAs (Ad-miR mABCG1 and Ad-miR neg) using the ViraPower Adenoviral Expression System (Invitrogen), according to the manufacturer's protocol as described above.

\section{Overexpression or microRNA-Mediated Inhibition of ABCG1 in RAW264.7 Cells by Adenoviral Vectors}

For in vitro infection, RAW264.7 cells were seeded in 6- or 12- well dishes in DMEM containing 10\% FBS. At 50-60\% confluence, cells were infected with 30 MOI of Ad-hABCG1, Ad-Luc, Ad-miR mABCG1 and Ad-miR neg. After $48 \mathrm{~h}$ of infection, the medium was replaced with DMEM containing 0.2\% BSA and cells were used for cholesterol efflux assays or protein expression analysis.

\section{Pulse-Chase Assays}

In the pulse-chase experiments, COS-7 cells transfected with phABCG1-FLAG were cultured in DMEM without cysteine and methionine (Sigma) for $60 \mathrm{~min}$ to deplete cells of methionine and cysteine. Then, a ${ }^{35}$ S-labeled methionine/cysteine mix was add- ed to the DMEM $(100 \mu \mathrm{Ci} / \mathrm{mL})$ and incubation conducted for $60 \mathrm{~min}$, followed by a chase period for the indicated times during which cells were cultured in DMEM supplemented with $1.5 \mathrm{mg} / \mathrm{mL} \mathrm{L}$-methionine and $0.5 \mathrm{mg} / \mathrm{mL} \mathrm{L-cysteine,} \mathrm{in} \mathrm{the} \mathrm{absence} \mathrm{or} \mathrm{presence}$ of SUAs. The cell lysates were subjected to immunoprecipitation by incubating with anti-FLAG M2 antibodies (Sigma). The precipitates were then washed and eluted by incubation in SDS sample buffer. Finally, the eluted proteins were separated by SDS-PAGE, and the gel was subjected to fluorography.

\section{Isolation of Mouse Peritoneal Macrophages and Livers after Oral Treatment with SUAs}

Seven-week-old male C57BL/6 mice (Clea Japan, Tokyo, Japan) were divided into 5 groups ( 4 mice per group) and orally treated with 5 or $20 \mathrm{mg} / \mathrm{kg}$ glimepiride or glibenclamide per day or the vehicle (0.5\% methylcellulose) for $5 \mathrm{~d}$. Mice were sacrificed to harvest mouse peritoneal macrophages. Phosphatebuffered saline (PBS) was injected into the peritoneal cavity. Fluid was then carefully collected and centrifuged at $3000 \mathrm{rpm}$. The supernatant was withdrawn, and the pellet was resuspended in DMEM. Then, the cells were plated onto a 6-well cell culture cluster for 1 hour, harvested and subjected to Western blot analyses. Protein extracts from liver tissue were prepared with T-Per (Pierce Chemical Co., Rockford, IL) in the presence of protease inhibitors (Roche Applied Science, Barcelona, Spain), and subjected to Western blot analyses as described above.

\section{In Vivo Macrophage RCT studies}

RAW264.7 cells were grown in suspension in RPMI 1640 supplemented with 10\% FBS and then radiolabeled with $5 \mu \mathrm{Ci} / \mathrm{mL}^{3} \mathrm{H}$-cholesterol and cholesterol enriched with $100 \mu \mathrm{g} / \mathrm{mL}$ acLDL for $48 \mathrm{~h}$. The cells were then washed, equilibrated, detached with cell scrapers, resuspended in RPMI 1640, and pooled before being injected into mice. Before the initial experiments, 7-week-old male C57BL/6 mice (Clea Japan, Tokyo, Japan) were divided into 3 groups (6 mice per group) and orally treated with $20 \mathrm{mg} / \mathrm{kg}$ glimepiride or glibenclamide per day or the vehicle (0.5\% methylcellulose) for $5 \mathrm{~d}$.

On the day of injection, mice were caged individually with unlimited access to food and water. ${ }^{3} \mathrm{H}$ cholesterol-labeled and acLDL-loaded RAW264.7 cells (typically $5.0 \times 10^{6}$ cells containing $7.5 \times 10^{6}$ counts per minute [cpm] in $0.5 \mathrm{~mL}$ RPMI 1640) were injected intraperitoneally as described previously ${ }^{21-23)}$. Blood samples were obtained from the tail vein under anesthesia prior to administration of the SUAs and at 
24 and $48 \mathrm{~h}$ after injection of RAW264.7 cells. Plasma was subjected to counting in a liquid scintillation counter (LSC). Feces were collected continuously from 0 to $48 \mathrm{~h}$ and stored at $4{ }^{\circ} \mathrm{C}$ before counting. At $48 \mathrm{~h}$ after injection, mice were exsanguinated, and then livers and bile were removed for the analyses described below.

The investigation was approved by the Internal Animal Care and Use Committee of the National Defense Medical College.

\section{Liver, Bile and Fecal Analyses}

Liver lipids were extracted as described previous$\mathrm{ly}^{21-23)}$. Briefly, a $50 \mathrm{mg}$ piece of tissue was homogenized in water, and lipids were extracted with a $2: 1$ (vol/vol) mixture of chloroform/methanol. The lipid layer was collected, evaporated, resuspended in a 3:2 ( $\mathrm{vol} / \mathrm{vol})$ mixture of hexane/isopropanol, and subjected to counting in an LSC. The bile was directly counted in an LSC. Total feces collected from 0 to $48 \mathrm{~h}$ were weighed and soaked in Millipore water $(1 \mathrm{~mL}$ water per $100 \mathrm{mg}$ feces) overnight at $4{ }^{\circ} \mathrm{C}$. An equal volume of ethanol was added the next day and the samples were homogenized with $200 \mu \mathrm{L}$ of the homogenized samples subjected to counting in an LSC. Results are expressed as a percentage of cpm injected.

\section{Determination of Lipid and Glucose Levels of Mice Treated with SUAs}

Plasma total cholesterol, HDL-cholesterol, triglyceride and glucose levels were determined by enzymatic measurement using commercially available kits (WAKO, Osaka, Japan).

\section{Statistical Analysis}

Student's $t$-test was performed as appropriate. A $p$ value of less than 0.05 was considered significant. Values are expressed as the mean $\pm \mathrm{SD}$.

\section{Results}

High Dose SUAs Respectively Inhibit and Promote ApoA-I - and HDL-Mediated Cholesterol Efflux, While Therapeutic Doses Effected No Change

We first investigated the effect of SUAs on apoA-Iand HDL-mediated cholesterol efflux from RAW264.7 cells, a murine macrophage cell line. As shown in Fig. 1A, SUAs did not change apoA-I-mediated cholesterol efflux up to $100 \mu \mathrm{M}$; however, at 500 $\mu \mathrm{M}$, glibenclamide, but not glimepiride, completely abolished the efflux, findings consistent with previous studies $2,12,14,17)$. As for apoA-I-mediated cholesterol efflux, at 0.1 to $100 \mu \mathrm{M}$, neither drug altered HDL- mediated cholesterol efflux, but at $500 \mu \mathrm{M}$, they significantly enhanced the efflux (Fig. 1B). In THP-1 macrophages, SUA doses of $500 \mu \mathrm{M}$ also markedly attenuated apoA-I-mediated efflux (Supplemental Fig. 1A) but not HDL-mediated efflux (Supplemental Fig. 1B).

High Dose SUAs Respectively Inhibit and Promote ABCA1 and ABCG1 Expressions, Though They Were Increased at Lower Doses

To further investigate the underlying molecular mechanisms, we determined ABCA1, ABCG1 and SR-BI expressions in RAW264.7 cells. ABCA1 protein expression was dose-dependently increased by both drugs in the 0.1 to $100 \mu \mathrm{M}$ range, but markedly decreased at $500 \mu \mathrm{M}$ (Fig. 1C). Both SUAs modestly increased ABCG1 protein expression in the 0.1 to 100 $\mu \mathrm{M}$ range and additional increases were observed at $500 \mu \mathrm{M}$. SR-BI protein expression was unchanged by the SUAs, except for a slight increase with 10-100 $\mu \mathrm{M}$ glimepiride and a slight decrease with $500 \mu \mathrm{M}$ glimepiride, (Fig. 1C).

We next measured mRNA levels of ABCA1/G1/ SR-BI to elucidate the effects of SUAs on protein levels. Glibenclamide dose-dependently (up to $100 \mu \mathrm{M}$ ) increased ABCA1 mRNA levels by up to 1.7 -fold (Fig. 2), paralleling changes in protein levels. At $500 \mu \mathrm{M}$, glibenclamide reduced ABCA1 mRNA levels by $40 \%$, which was relatively less than the reduction in protein expression (Fig. 1C). Glimepiride did not affect ABCA1 mRNA levels, except for a significant increase at $100 \mu \mathrm{M}$, indicating that a marked reduction in ABCA1 protein expression (Fig. 1C) was not attributable to mRNA reduction.

Responses in ABCG1 mRNA expression differed between glibenclamide and glimepiride. At 1 to $100 \mu \mathrm{M}$, glibenclamide dose-dependently increased ABCG1 mRNA levels, whereas glimepiride did not. At $500 \mu \mathrm{M}$, glibenclamide induced a non-significant 2.2-fold increase in mRNA levels, which was not in accordance with the marked increase in protein levels (Fig. 1C). Furthermore, in spite of markedly increasing protein levels, glimepiride decreased ABCG1 mRNA levels. Taken together, these results indicate that the marked changes in the protein expressions of ABCA1/G1 brought about by SUAs at high doses were independent of mRNA levels. SR-BI mRNA levels were increased by glibenclamide at $10-100 \mu \mathrm{M}$, in parallel with protein levels (Fig. 1C), whereas they were not changed by glimepiride.

We also investigated the effects of the SUAs on mRNA levels using THP-1 macrophages. As shown in Supplemental Fig. 2, the changes SUAs $(1-100 \mu \mathrm{M})$ 
A
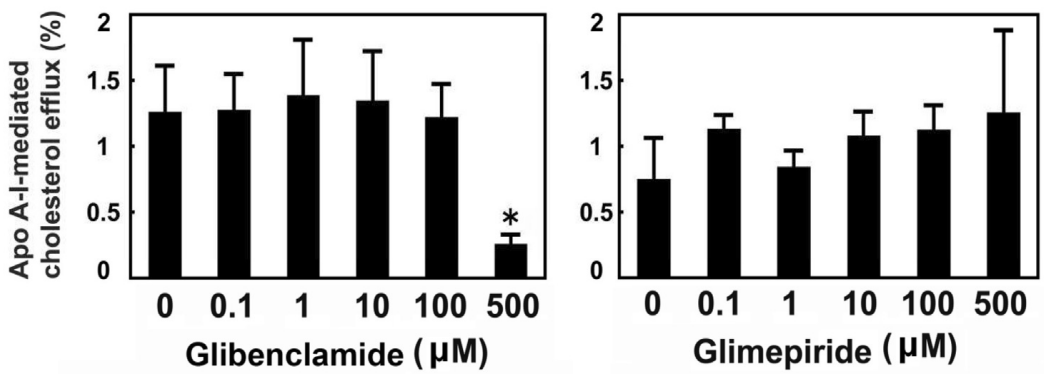

B
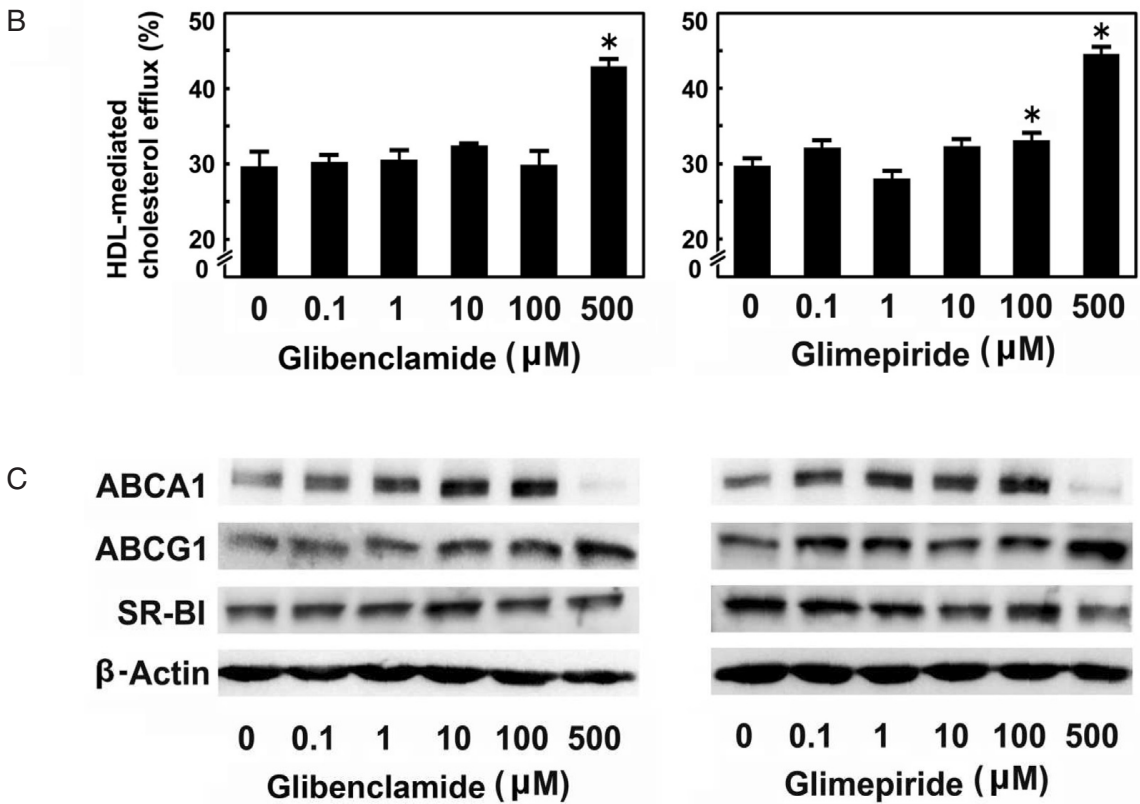

D
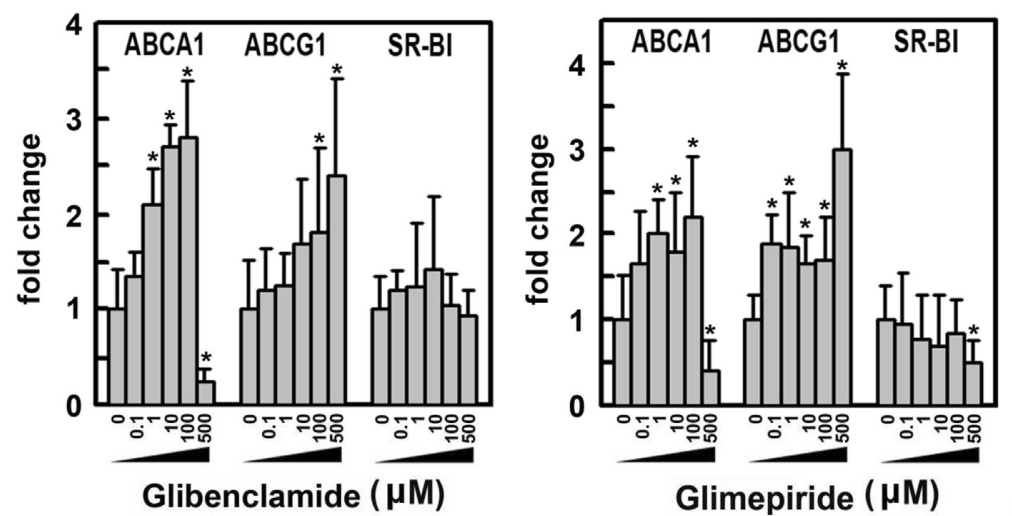

Fig. 1. Effects of SUAs on apoA-I- and HDL-mediated cholesterol efflux and ABCA1, ABCG1 and SR-BI protein levels in RAW264.7 cells

A, B, After ${ }^{3} \mathrm{H}$-cholesterol labeling, indicated doses of SUAs or the vehicle were added to the cultures, which were then incubated in the presence of $50 \mu \mathrm{g} / \mathrm{mL}$ HDL or $10 \mu \mathrm{g} / \mathrm{mL}$ human apoA-I for $24 \mathrm{~h}$. Determination of cholesterol efflux from the cells was performed as described in Methods. The results are presented as the mean \pm SD of 6 replicate wells. The results are representative of 3 or more experiments. C, RAW264.7 cells were lysed and subjected to Western blot analysis $24 \mathrm{~h}$ after treatment with indicated doses of SUAs or the vehicle in the absence (for ABCG1/SR-BI) or presence (for ABCA1) of $0.3 \mathrm{mM}$ cAMP. The results are from 3 separate experiments that yielded similar results. D, Protein levels were quantified as described in Methods. The results are presented as the mean \pm SD. ${ }^{*} p<0.05$ vs. control. 

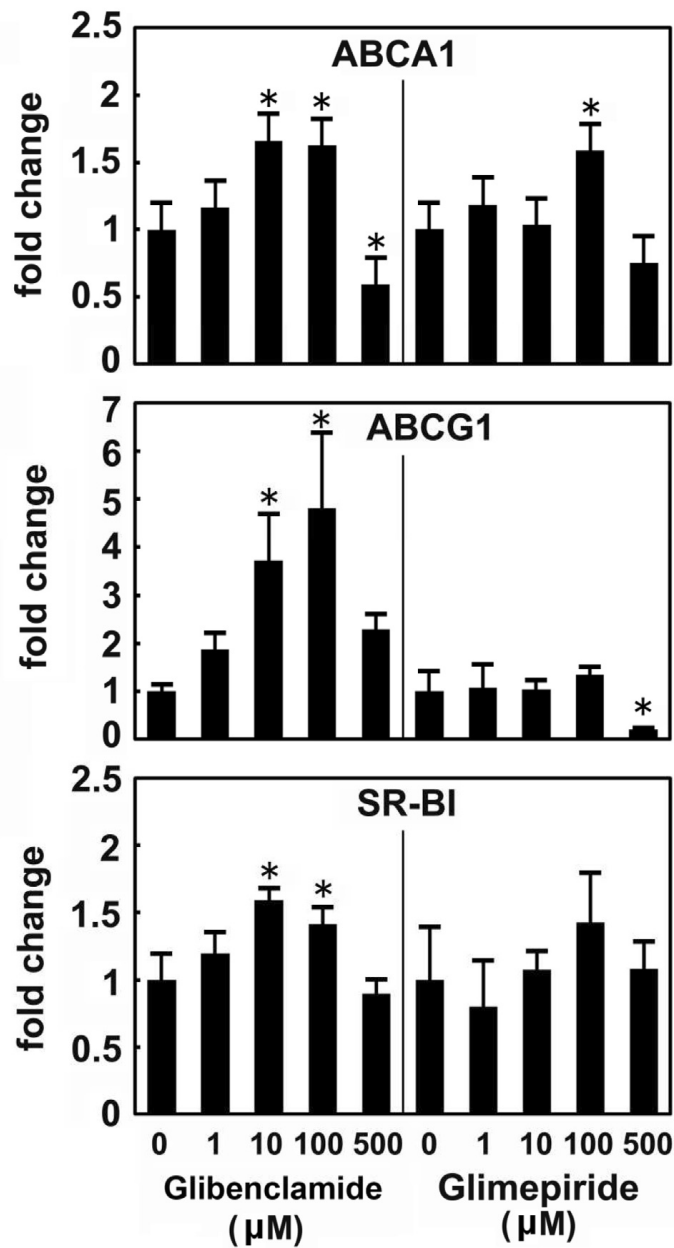

Fig. 2. Effects of SUAs on mRNA levels of ABCA1, ABCG1 and SR-BI in RAW264.7 cells

RAW264.7 cells were treated with the indicated dose of SUAs or the vehicle for $24 \mathrm{~h}$ in the absence (for ABCG1 and SR-BI) and presence of $0.3 \mathrm{mM}$ cAMP (for ABCA1). Real-time quantitative RT-PCR was performed to determine ABCA1, ABCG1 and -BI mRNA levels as described in Methods. The mRNA levels of each gene were standardized for GAPDH levels. The results from 3 replicate wells are expressed relative to the controls and presented as the mean \pm SD. The results are representative of 3 or more experiments. ${ }^{*} p<0.05$ vs. control.

brought about in ABCA1 and ABCG1 mRNA levels in THP-1 macrophages were similar to those in RAW264.7 cells, indicating that these changes were not species specific. At $500 \mu \mathrm{M}$, however, glibenclamide had a stimulatory effect on ABCG1 expression in the macrophages but not in RAW264.7 cells, while glimepiride did not affect its expression.

To follow up the observation that glibenclamide (1-100 $\mu \mathrm{M})$ dose-dependently enhanced ABCA1/G1 protein (Fig. 1C) and mRNA levels (Fig. 2), we performed luciferase assays using human ABCA1 and
A
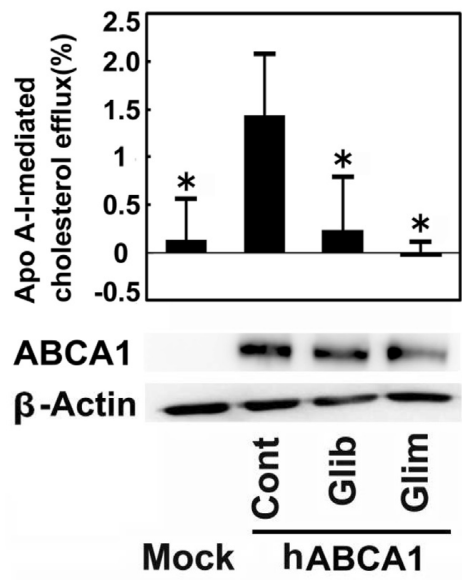

B

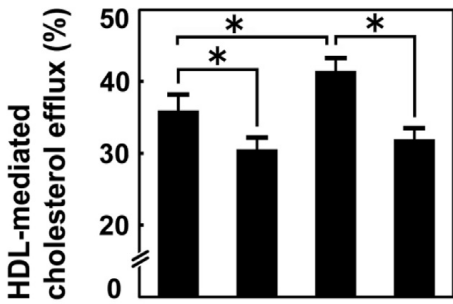

\section{SR-BI}

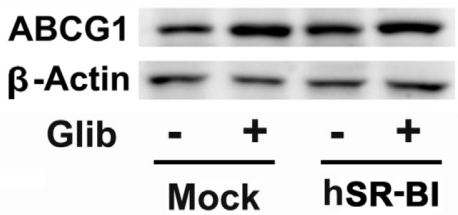

Fig. 3. Effects of SUAs on ABCA1- and SR-BI-mediated cholesterol efflux

A, HEK293 cells were transiently transfected with phABCA1 or an empty vector (mock). B, SR-BI-expressing BHK-21 cells were used as described in Methods. After ${ }^{3} \mathrm{H}$-cholesterol labeling, $500 \mu \mathrm{M}$ glibenclamide (Glib), glimepiride (Glim) or the vehicle was added to the cultures, which were then incubated in the presence of $10 \mu$ $\mathrm{g} / \mathrm{mL}$ apoA-I (for HEK293) or $50 \mu \mathrm{g} / \mathrm{ml} \mathrm{HDL}$ (for BHK-21) for $24 \mathrm{~h}$. The results are presented as the mean \pm SD of 6 replicate wells. The results are representative of 3 or more experiments. ${ }^{*} p<$ 0.05 vs. control or values as indicated. A, B: Western blot analysis was performed $24 \mathrm{~h}$ after treatment with SUAs using corresponding antibodies.

ABCG1 promoter-reporter constructs in order to determine whether the SUAs transactivate these genes. To our surprise, both decreased human ABCA1 and ABCG1 A and B promoter activity in a dose-dependent fashion (Supplemental Fig.3).

\section{High-Dose SUAs Inhibit ABCA1-Dependent Cholesterol efflux}

To confirm the effect of glibenclamide as an ABCA1 inhibitor, we determined apoA-I-mediated 
cholesterol efflux using hABCA1-overexpressing HEK293 cells. As shown in Fig. 3A, at $500 \mu \mathrm{M}$, both glibenclamide and glimepiride almost completely abolished ABCA1-mediated cholesterol efflux due to apoA-I. ABCA1 protein levels; however, they were modestly decreased by the SUAs in HEK293 cells (Fig. 3A) and markedly reduced in RAW264.7 cells (Fig. 1C). These observations indicate that inhibition of ABCA1 functionality is an effect of the SUA class.

\section{High-Dose Glibenclamide Inhibits SR-BI-Dependent Cholesterol efflux}

We then performed experiments using SR-BIoverexpressing cells to confirm the effects of the SUAs. In the absence of SR-BI overexpression, $500 \mu \mathrm{M}$ glibenclamide reduced HDL-mediated cholesterol efflux from mock-transfected BHK-21 cells (Fig. 3B), which was opposite the result in RAW264.7 cells (Fig. 1B). In the case of SR-BI expression, there was a significant increase in HDL-mediated efflux (15\%). High-dose glibenclamide completely canceled the SR-BI-mediated enhancement of cholesterol efflux (Fig. 3B). Although glibenclamide decreased SR-BI protein levels in SR-BI-overexpressing cells, endogenous ABCG1 protein levels increased under the same conditions. Increased endogenous ABCG1 protein levels were also noted in the absence of SR-BI-overexpression (Fig. 3B). Supplemental Fig. 1C shows that at high doses, the SUAs markedly inhibited SR-BI protein expression in THP-1 cells, different to the response in RAW264.7 cells (Fig. 1C). These observations thus support the previous finding that glibenclamide inhibits SR-BI functionality and attenuates SR-BI protein expression at posttranslational levels in some cells.

\section{High-Dose Glibenclamide Promotes HDL-Mediated Efflux Independently of ABCG1}

Previous studies did not address the effects of SUAs on ABCG1 function. We therefore generated adenoviral vectors for overexpression (Ad-hABCG1) and a knockdown (Ad-miR mABCG1) of ABCG1 to investigate whether increased ABCG1 expression due to high-dose glibenclamide promoted HDL-mediated efflux in RAW267.4 cells (Fig. 1B \& C).

As expected, transduction of Ad-miR mABCG1 in RAW264.7 cells brought about a marked knockdown of ABCG1 (Fig.4A), resulting in a slight but significant increase in HDL-mediated cholesterol efflux. Although glibenclamide enhanced HDL-mediated cholesterol efflux in both the control and knockdown of ABCG1, the magnitude of enhancement seemed greater in the latter. Glibenclamide increased ABCG1 protein levels in whole cell (WC) extracts both in the absence and presence of Ad-miR mABCG1. We measured ABCG1 protein levels in the $P M$ fraction to find that, under the knockdown of ABCG1, ABCG1 expression was markedly attenuated by glibenclamide in PM as compared to WC. Our ABCG1 overexpression study confirmed the previous observation that such manipulation induced a slight but significant increase in HDL-mediated cholesterol efflux $^{4}$. Additionally, in the presence of Ad-hABCG1, high-dose glibenclamide promoted HDL-mediated cholesterol efflux to a similar extent to that in the control virus ( $13 \%$ in control virus vs. $12 \%$ in AdABCG1); however, it was puzzling that glibenclamide substantially decreased the originally overexpressed ABCG1 protein levels in WC. We again observed the differential effects of glibenclamide on ABCG1 protein levels between WC and PM fractions; namely, overexpressed ABCG1 in PM was not affected by glibenclamide, in sharp contrast to whole cell, in which glibenclamide downregulated exogenous ABCG1. Although the precise molecular mechanisms remain unclear, glibenclamide might affect ABCG1 protein levels in distinct cell compartments except for PM, and this effect might differ between endogenous and exogenous ABCG1.Taken together, these results indicate that high-dose glibenclamide-mediated enhancement of HDL efflux cannot be fully explained using ABCG1.

Here the question arises why high-dose glibenclamide should increase endogenous ABCG1 protein expression in RAW264.7 cells but decrease overexpressed ABCG1 protein levels in them (Fig. 4B) and endogenous ABCG1 protein levels in THP-1 cells (Supplemental Fig. 1C). To elucidate this discrepancy, we performed metabolic labeling pulse-chase experiments. We first performed the experiments using RAW264.7 cells and the primary antibody against ABCG1; however, conclusive results could not be obtained, likely due to low transfection efficiency. We therefore used COS-7 cells transfected with a FLAGtagged ABCG1 expression vector. As shown in Fig. $4 \mathrm{C}$, glibenclamide accelerated ABCG1 protein degradation, which would have resulted in the observed decreases mentioned above. Since COS-7 cells may have characteristics which differ from macrophage, including RAW264.7 cells, other factors may come into play in "unmodified" RAW264.7 cells.

We summarize the complex effects of high-dose glibenclamide on $\mathrm{mRNA} /$ protein expressions of ABCA1/G1/SR-BI in macrophages or other cell lines and apoA-I/HDL-mediated cholesterol efflux in Supplemental Table 1. 
A

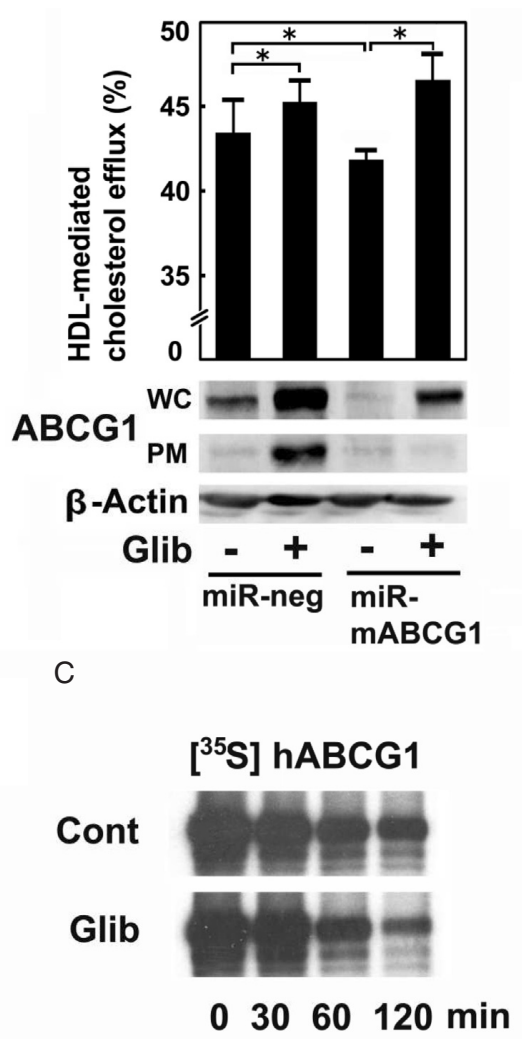

B

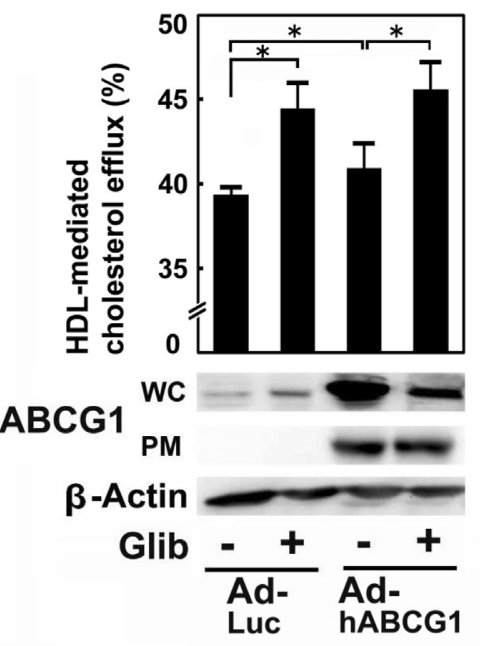

Fig.4. Effect of glibenclamide on ABCG1-mediated HDL efflux in RAW264.7 cells and protein degradation of ABCG1

RAW264.7 cells were treated with adenoviral vectors expressing human ABCG1/luciferase (Luc) (B)/microRNA (miR) for mouse ABCG1/ miR neg (A) as described in Methods. After ${ }^{3} \mathrm{H}$-cholesterol labeling, $500 \mu \mathrm{M}$ glibenclamide (Glib) or the vehicle was added to the cultures, which were then incubated in the presence of $50 \mu \mathrm{g} / \mathrm{mL}$ HDL for $24 \mathrm{~h}$. The results are presented as the mean $\pm \mathrm{SD}$ of 3 replicate wells. The results are representative of 3 or more experiments. ${ }^{*} p<0.05$ vs. control or values as indicated. After transduction of the viruses, the cells were treated with $500 \mu \mathrm{M}$ of glibenclamide or the vehicle for $24 \mathrm{hr}$, whole cell (WC) lysates or plasma membrane (PM) fraction were isolated as described in Methods, and then subjected to Western blot. C, COS-7 cells transiently transfected with phABCG1-FLAG were subject to pulse-chase analysis as described in Methods. The cells were pulsed with $0.2 \mathrm{mCi} / \mathrm{mL}^{35} \mathrm{~S}$-methionine/cysteine for $60 \mathrm{~min}$, then incubated for the chase reaction in the absence or presence of Glib $(500 \mu \mathrm{mol} / \mathrm{L})$ for the indicated time. Proteins were immunoprecipitated using the M2 anti-FLAG antibody, and ${ }^{35}$ S-labeled ABCA1 and ABCG1 were visualized by autoradiography. The results are representative of 3 experiments.

Table 1. Plasma lipids levels obtained from mice orally treated with glibenclamide or glimepiride

\begin{tabular}{|c|c|c|c|c|c|c|}
\hline & \multicolumn{2}{|c|}{ Cont } & \multicolumn{2}{|c|}{ Glibenclamide } & \multicolumn{2}{|c|}{ Glimepiride } \\
\hline & $0-d$ & $5-d$ & $0-d$ & $5-d$ & $0-d$ & $5-d$ \\
\hline Total cholesterol, mg/dl & $71 \pm 10$ & $67 \pm 9$ & $71 \pm 11$ & $68 \pm 7$ & $69 \pm 5$ & $67 \pm 8$ \\
\hline HDL-cholesterol, mg/dl & $53 \pm 6$ & $44 \pm 6$ & $53 \pm 7$ & $42 \pm 4$ & $51 \pm 7$ & $43 \pm 5$ \\
\hline Triglycerides, mg/dl & $23 \pm 7$ & $21 \pm 4$ & $25 \pm 5$ & $23 \pm 5$ & $23 \pm 5$ & $22 \pm 6$ \\
\hline
\end{tabular}

Abbreviations: HDL, high density-lipoprotein. Values are the mean \pm SD.

Mice were orally treatted with glibenclamide, glimepiride $(20 \mathrm{mg} / \mathrm{kg}$ for each), and the vehicle (Cont) for 5 days. Blood was obtained before $(0 \mathrm{~d})$ and after $(5 \mathrm{~d})$ treatments, and plasma lipids were determined as described in Methods.

\section{SUAs Did Not Affect Total RCT in Vivo}

Finally, we investigated the effects of therapeutic doses of SUAs on ABCA1/ABCG1/SRBI protein expressions in peritoneal macrophages and livers, and overall RCT in mice in vivo. As shown in Fig. 5A, 5 days of oral preloading with glimepiride, but not glibenclamide, increased ABCA1protein expressions in peritoneal macrophages; however, ABCG1 and SR-BI expressions were not changed by either SUA. With regard to protein expression in the liver where ABCG1 
A

Peritoneal macrophages

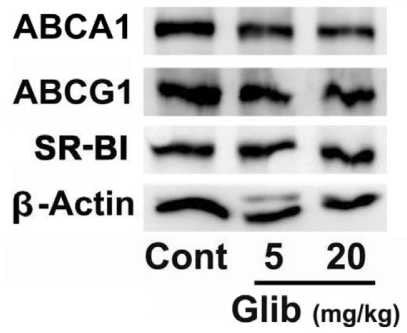

B

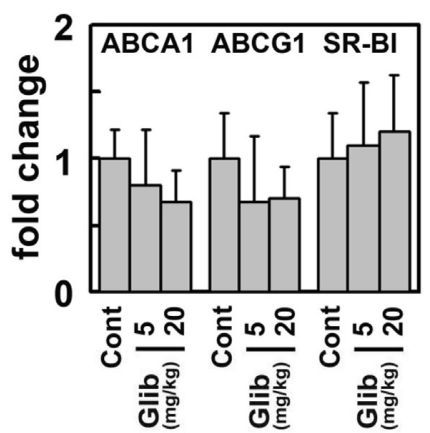

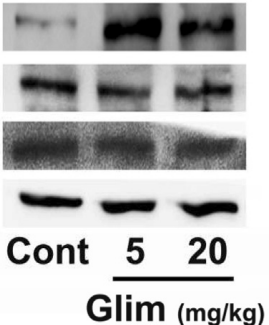

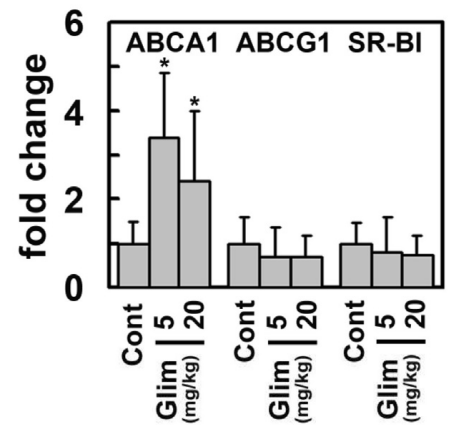

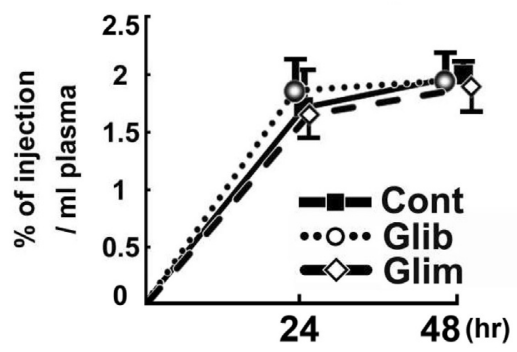

$\mathrm{F}$

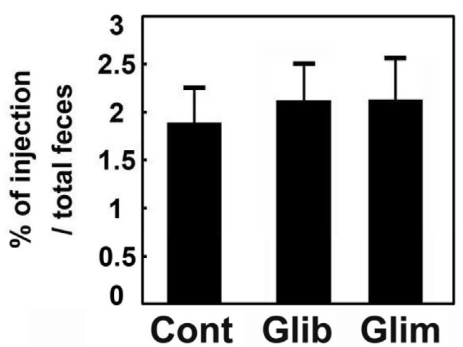

C

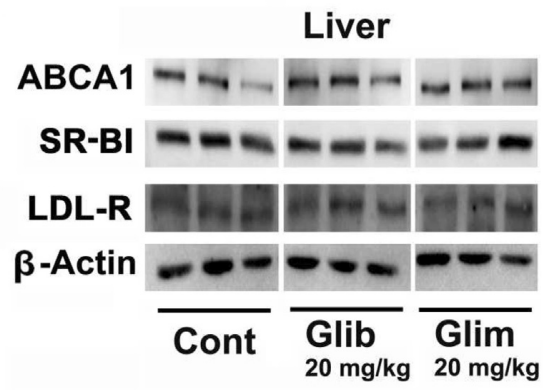

D

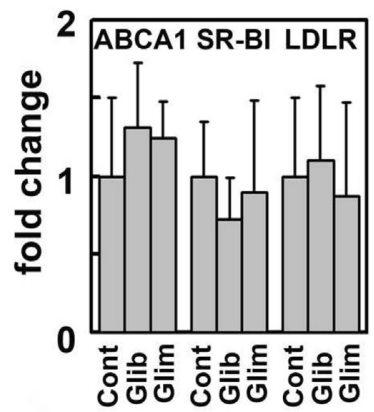

Fig. 5. Effects of SUAs on ABCA1, ABCG1 and SR-BI expressions in mouse peritoneal macrophages and liver, and RCT in vivo

Seven-week-old male C57BL/6 mice were orally treated with 5 (only for Western blots of peritoneal macrophages) or $20 \mathrm{mg} / \mathrm{kg}$ glimepiride or glibenclamide per day, or the vehicle. Five days after treatment with SUAs, resident peritoneal macrophages (A, B) and the liver (C. D) were isolated and subjected to Western blot analysis as described in Methods. The results are from 3 separately performed experiments that yielded similar results. Protein levels in peritoneal macrophages (B) and the liver (D) were quantified as described in Methods. The results are presented as the mean \pm SD. ${ }^{*} p<0.05$ vs. control. For the in vivo RCT assay, $3 \mathrm{~d}$ after treatment with SUAs, ${ }^{3} \mathrm{H}$-cholesterol-labeled RAW264.7 cells were intraperitoneally injected as described in Methods. Blood samples (C) obtained from the mice 24 and $48 \mathrm{~h}$ after injection were subjected to ${ }^{3} \mathrm{H}$ counting. Feces (D) collected continuously from 0 to $48 \mathrm{~h}$ were also subjected to ${ }^{3} \mathrm{H}$ counting. Data are expressed as percent counts relative to total injected tracer (means $\pm \mathrm{SD}, n=6$ for each group).

proteins were not detectable, SUAs did not affect ABCA1, SR-BI, of LDL-R protein expression (Fig. 5B). We also observed that SUA loading at 20 $\mathrm{mg} / \mathrm{kg}$ did not modulate lipid profiles, as shown in the Table 1. When $20 \mathrm{mg} / \mathrm{kg}$ daily of each drug was orally administered for 3 days, RCT assays revealed that the appearance of ${ }^{3} \mathrm{H}$-cholesterol in plasma (Fig. 5C), liver and bile (data not shown) did not differ among groups. Further, fecal excretions of the ${ }^{3} \mathrm{H}$-tracer in the SUAs were comparable among groups (Fig. 5D).
Activities of plasma LCAT, another factor regulating RCT, were found to be comparable between the treatment with $20 \mathrm{mg} / \mathrm{kg}$ SUAs and the vehicle. We further measured blood glucose and body weight to find that these parameters did not differ by SUAs or vehicle (Supplemental Table 2).

\section{Discussion}

We undertook the present study to better under- 
stand the previous finding that high-dose glibenclamide had unfavorable effects on ABCA1- and SRBI- mediated cholesterol efflux from macrophages, an initial step in reverse cholesterol transport. We performed detailed in vitro experiments using different doses of the SUAs glibenclamide and glimepiride as well as various cell types, including RAW264.7, HEK293, BHK-21, and THP-1 cells, and observed the complex nature of the effects of SUAs on the cholesterol efflux process for the first time. High-dose (500 $\mu \mathrm{M})$ glibenclamide not only inhibited ABCA1 function and apoA-I-mediated cholesterol efflux, but also attenuated $A B C A 1$ protein expression. Glimepiride, on the other hand, did not affect apoA-I-mediated cholesterol efflux from RAW264.7 cells, but like glibenclamide, markedly decreased ABCA1 protein expression and ABCA1-mediated cholesterol efflux from HEK293 cells transfected with ABCA1. High-dose SUAs increased ABCG1 expression in RAW264.7 cells and promoted HDL-mediated cholesterol efflux in an ABCG1-independent manner; however, at lower doses (including the therapeutic range), the SUAs increased $A B C A 1$ and $A B C G 1$ protein expressions in a dose-dependent manner but did not affect cholesterol efflux from macrophages. Supporting the in vitro findings, the SUAs did not modulate overall RCT in vivo.

The present study confirmed the previous findings ${ }^{2,10-12)}$ that high-dose glibenclamide completely inhibited apoA-I-mediated cholesterol efflux from RAW264.7 cells and HEK293 cells transfected with ABCA1. Although high-dose glimepiride also induced a marked reduction in ABCA1 proteins without inhibiting apoA-I-mediated cholesterol efflux in RAW264.7 cells, it canceled ABCA1-mediated lipid efflux from HEK293 cells overexpressing ABCA1. Taking these results together, the inhibitory effect on ABCA1 is considered to be an effect of the SUA class. Indeed, 2 other SUAs, tolbutamide and gliclazide, also inhibited ABCA1-mediated cholesterol efflux (data not shown).

SUAs stimulate insulin secretion from pancreatic $\beta$ cells by binding to SU receptors (SUR; SUR1 or SUR2), which form ATP-sensitive KaTP channels together with Kir6.x (Kir6.1 or Kir6.2) ${ }^{24)}$. The SUR subunits belong to the $\mathrm{ABC}$ transporter family, as do $A B C A 1$ and $A B C G 1$, providing a theoretical basis for the observed inhibitory effect of SUAs on ABCA1. This would also be a basis for the effects of SUAs on other ABC transporters, such as cystic fibrosis transmembrane conductance regulator (CFTR) ${ }^{25)}$, p-glycoprotein ${ }^{26)}$, and bile salt export pump ${ }^{27)}$. Although unconfirmed, it is likely that SUAs directly bind ABCA1 and other $\mathrm{ABC}$ transporters since they have been seen to bind SUR ${ }^{24)}$ and CFTR ${ }^{28)}$. Also, Nieland et al. ${ }^{14)}$ reported that glibenclamide competed in binding between apoA-I and ABCA1, indicating a direct interaction between SUAs and ABCA1. An alternative explanation would be that SUAs inhibit ABCA1 by interacting with macrophage SURs but we believe it unlikely because the concentration of glibenclamide required to inhibit ABCA1 is substantially higher than that reported for in vitro Ki for SUR1/2 ${ }^{24}$. Inhibition of apoA-I mediated cholesterol efflux by high-dose SUAs poses a further question: whether SUAs accelerate $\mathrm{ABCA} 1$ protein degradation. Although this is likely to be correct based on the fact that the ABCA1 protein half life is relatively short ${ }^{29)}$, we could not successfully demonstrate this in the pulse-chase assay due to technical problems.

A novel finding of the present study was that glibenclamide did not affect ABCG1-mediated cholesterol efflux due to HDL, unlike ABCA1-mediated efflux. In RAW264.7 cells, the stimulatory effect of high-dose SUAs was also evident under overexpression and knockdown of ABCG1 (Fig. 4A and 4B). These observations imply that among $\mathrm{ABC}$ transporters, ABCG1 may not be a good target for SUAs; however, ABCG1 reportedly forms a homodimer ${ }^{30,31)}$; therefore, in theory, ABCG1 could form a heterodimer with other unknown $\mathrm{ABC}$ transporters, similar to ABCG5/G8. In this regard, the results of ABCG1 knockdown should be interpreted with caution since the knockdown might not completely abolish ABCG1 functions. High-dose glibenclamide reportedly exerts an inhibitory effect on acyl-CoA cholesterol acyltransferase $(A C A T)^{32)}$. Since ACAT inhibitors are well known to enhance HDL-induced cholesterol efflux from murine macrophages ${ }^{33,34)}$, this could be a mechanistic explanation for the observed enhanced HDLmediated efflux by high-dose glibenclamide.

The present study also demonstrated that SUAs inhibit SR-BI functionality (Fig. 3B), a finding consistent with a previous study ${ }^{14)}$. Although high-dose SUAs did not affect SR-BI expression in RAW264.7 cells (Fig. 1C), they markedly reduced SR-BI expression in THP-1 macrophages (Supplemental Fig. 1C) and BHK-21 cells overexpressing SR-BI (Fig.3B). These observations therefore indicate that the inhibitory effects of SUAs on SR-BI functionality and protein expression are, at least in part, cell type-dependent.

Previous studies demonstrated that high-dose glibenclamide inhibits ABCA1- and SR-BI-mediated cholesterol efflux but did not elucidate the underlying mechanisms. In the present study, we took a further step and revealed that glibenclamide markedly re- 
duced ABCA1 protein levels. Surprisingly, high-dose SUAs increased ABCG1 protein expression in RAW264.7 cells (Fig. 1C) and BHK-21 cells (Fig. 3B), but not in THP-1 macrophages (Supplemental Fig. 1C) or RAW264.7 cells overexpressing ABCG1 (Fig.4B). They also accelerated protein degradation in exogenously overexpressed ABCG1 in COS-7 cells. Taken together, these results indicate that the effects of high-dose SUAs on ABCG1 expression are dependent on cell type, similar to SR-BI.

It is noteworthy that high-dose SUAs diminished ABCA1/G1/SR-BI expressions (Supplemental Fig. 1C) in THP-1 macrophages. They also markedly attenuated apoA-I-mediated cholesterol efflux (Supplemental Fig. 1A) while HDL-mediated cholesterol efflux was not affected, despite extremely low levels of ABCA1/G1/SR-BI (Supplemental Fig. 1B). Previous studies observed that probucol, a lipid-lowering drug, had an inhibitory effect on ABCA1 function ${ }^{35)}$, but increased $A B C A 1^{35)}$ and SR-BI protein expression ${ }^{36}$ by delaying protein degradation. In conjunction with our observations that SUAs affected both the expression and function of SR-BI in parallel with $\mathrm{ABCA} 1 / \mathrm{G} 1$, it is possible that the inhibitory activities of SUAs may be directed toward other unknown ABC transporters which influence lipid transport and ABCA1/G1/SR-BI expressions. This could explain the observation that HDL-mediated cholesterol efflux was maintained despite a marked reduction in ABCA1/G1/SR-BI expression with high-dose SUAs. Further studies are therefore needed to clarify the overall mechanisms of the complex effects of highdose SUAs on ABCA1/G1/SR-BI expressions and functionality.

A more important issue to address in the present study was the effects of lower concentrations (0.1-100 $\mu \mathrm{M}$, including the therapeutic range) of SUAs on ABCA1/G1/SR-BI expressions and cholesterol efflux. Our results showed a dose-dependent increase in ABCA1/G1 expressions in RAW264.7 cells (Fig. 1C) and ABCA1/G1/SR-BI expressions in THP-1 macrophages (Supplemental Fig. 1C). Nonetheless, these changes did not translate into enhanced HDL- or apoA-I-mediated cholesterol efflux. A reasonable explanation for this discrepancy might be that the inhibitory effects of SUAs on ABCA1/SR-BI functionality could counteract the increased expressions of these molecules. Supporting this hypothesis are previous observations ${ }^{12,37)}$ that $100 \mu \mathrm{M}$ of glibenclamide effectively inhibited ABCA1-mediated cholesterol efflux. The dose-dependent increase in protein levels of ABCA1 induced by both drugs and those of ABCG1 by glibenclamide (Fig. 1C) appeared to be in parallel with the corresponding changes in mRNA levels (Fig. 2) in RAW264.7 cells.

In THP-1 macrophages, the changes in mRNA levels account for those in protein levels of ABCA1/G1/SR-BI. We therefore investigated the effects of SUAs on ABCA1/G1 promoter activity but the results showed that the SUAs attenuated these promoters (Supplemental Fig. 3). We also found that they did not affect the stability of ABCA1/G1 mRNA (data not shown); however, as the ABCA1 and ABCG1 promoter constructs used in the present study might lack some elements necessary for transactivation by SUAs, further investigation of SUA-mediated ABCA1/G1 expression is needed. Overall, our observations suggest that lower doses $(0.1-100 \mu \mathrm{M})$ of SUAs did not adversely affect cholesterol efflux from macrophages.

Finally, we performed in vivo RCT experiments in order to further assess the overall effect of lower doses of SUAs on mice. The results showed that oral treatment with SUAs did not affect overall RCT in vivo or lipid levels. Since SUAs also did not affect blood glucose levels (Supplemental Table 2), the question of whether the administered doses of SUAs were sufficient arises; however, Remedi et al. ${ }^{38)}$ reported that, when mice were treated with glibenclamide, the initial decrease in fed blood glucose at day 1 was lost within a few days, and then fed blood glucose was significantly higher than in controls after 4-5 days, presumably due to loss of insulin secretory capacity caused by $\beta$-cell hyperexcitability; therefore, it is not surprising that SUA treatment for 5 days did not affect fed glucose levels in our data. Although we did not know the levels of circulating SUAs in the present study, therapeutic glibenclamide doses in humans are typically around $0.05 \mathrm{mg} / \mathrm{kg} /$ day. Our doses (5-20 $\mathrm{mg} / \mathrm{kg} /$ day) should therefore have been high enough in mice.

Detailed analysis of in vivo studies seems to indicate that glimepiride, but not glibenclamide, increased ABCA1 expression in peritoneal macrophages (Fig. 5A), a theoretical advantage of the former leading to promoted RCT; however, these results should be interpreted with caution since the very high peak concentrations achieved by oral administration of $5-20 \mathrm{mg} / \mathrm{kg}$ glibenclamide/glimepiride in mice might not be comparable to the human setting. Another limitation of this in vivo experiment is species differences in cholesterol ester transfer protein activities between mice and humans; the former lacking but the latter abundant. In this regard, the finding obtained from mice may simply not apply to the human setting. Since both ABCA1 in macrophages ${ }^{39)}$ and SR-BI in 
the liver ${ }^{40)}$ have been reported to positively contribute to in vivo RCT, the inhibitory effects of glimepiride on ABCA1/SR-BI function might offset the increased $A B C A 1$ in macrophages.

In conclusion, the present study demonstrated that high-dose SUAs inhibit the functionality of ABCA1 and SR-BI, but not ABCG1, and either increased or decreased expressions of these molecules, at least in part, in a cell-type-dependent manner, whereas at lower, therapeutic doses, SUAs do not have unfavorable effects on cholesterol efflux in vitro or overall RCT in vivo. These results therefore indicate that SUAs do not exert the adverse effects on RCT that were previously anticipated, based on observations of glibenclamide in particular.

\section{References}

1) Lewis GF, Rader DJ: New insights into the regulation of HDL metabolism and reverse cholesterol transport. Circ Res, 2005; 96: 1221-1232

2) Wang N, Silver DL, Thiele C, Tall AR: ATP-binding cassette transporter A1 (ABCA1) functions as a cholesterol efflux regulatory protein. J Biol Chem, 2001; 276: 23742 23747

3) Yokoyama S: ABCA1 and biogenesis of HDL. J Atheroscler Thromb, 2006; 13: 1-15

4) Wang N, Lan D, Chen W, Matsuura F, Tall AR: ATPbinding cassette transporters G1 and G4 mediate cellular cholesterol efflux to high-density lipoproteins. Proc Natl Acad Sci U S A, 2004; 101: 9774-9779

5) Ohgami N, Miyazaki A, Sakai M, Kuniyasu A, Nakayama $\mathrm{H}$, Horiuchi S: Advanced glycation end products (AGE) inhibit scavenger receptor class B type I-mediated reverse cholesterol transport: a new crossroad of AGE to cholesterol metabolism. J Atheroscler Thromb, 2003; 10: 1-6

6) Haffner SM, Lehto S, Ronnemaa T, Pyorala K, Laakso M: Mortality from coronary heart disease in subjects with type 2 diabetes and in nondiabetic subjects with and without prior myocardial infarction. N Engl J Med, 1998; 339: 229-234

7) Sarwar N, Gao P, Seshasai SR, Gobin R, Kaptoge S, Di Angelantonio E, Ingelsson E, Lawlor DA, Selvin E, Stampfer M, Stehouwer CD, Lewington S, Pennells L, Thompson A, Sattar N, White IR, Ray KK, Danesh J: Diabetes mellitus, fasting blood glucose concentration, and risk of vascular disease: a collaborative meta-analysis of 102 prospective studies. Lancet, 2010; 375: 2215-2222

8) Oyama T, Saiki A, Endoh K, Ban N, Nagayama D, Ohhira M, Koide N, Miyashita Y, Shirai K: Effect of acarbose, an alpha-glucosidase inhibitor, on serum lipoprotein lipase mass levels and common carotid artery intima-media thickness in type 2 diabetes mellitus treated by sulfonylurea. J Atheroscler Thromb, 2008; 15: 154-159

9) Kar P, Holt RI: The effect of sulphonylureas on the microvascular and macrovascular complications of diabetes. Cardiovasc Drugs Ther, 2008; 22: 207-213
10) Fielding PE, Nagao K, Hakamata H, Chimini G, Fielding CJ: A two-step mechanism for free cholesterol and phospholipid efflux from human vascular cells to apolipoprotein A-1. Biochemistry, 2000; 39: 14113-14120

11) Feng B, Tabas I: ABCA1-mediated cholesterol efflux is defective in free cholesterol-loaded macrophages. Mechanism involves enhanced $\mathrm{ABCA} 1$ degradation in a process requiring full NPC1 activity. J Biol Chem, 2002; 277: 43271-43280

12) Burgess JW, Kiss RS, Zheng H, Zachariah S, Marcel YL: Trypsin-sensitive and lipid-containing sites of the macrophage extracellular matrix bind apolipoprotein A-I and participate in ABCA1-dependent cholesterol efflux. J Biol Chem, 2002; 277: 31318-31326

13) Marguet D, Luciani MF, Moynault A, Williamson P, Chimini G: Engulfment of apoptotic cells involves the redistribution of membrane phosphatidylserine on phagocyte and prey. Nat Cell Biol, 1999; 1: 454-456

14) Nieland TJ, Chroni A, Fitzgerald ML, Maliga Z, Zannis VI, Kirchhausen T, Krieger M: Cross-inhibition of SR-BIand ABCA1-mediated cholesterol transport by the small molecules BLT-4 and glyburide. J Lipid Res, 2004; 45: 1256-1265

15) Ayaori M, Sawada S, Yonemura A, Iwamoto N, Ogura M, Tanaka N, Nakaya K, Kusuhara M, Nakamura H, Ohsuzu F: Glucocorticoid receptor regulates ATP-binding cassette transporter-A1 expression and apolipoprotein-mediated cholesterol efflux from macrophages. Arterioscler Thromb Vasc Biol, 2006; 26: 163-168

16) Nakaya K, Ayaori M, Hisada T, Sawada S, Tanaka N, Iwamoto N, Ogura M, Yakushiji E, Kusuhara M, Nakamura H, Ohsuzu F: Telmisartan enhances cholesterol efflux from THP-1 macrophages by activating PPARgamma. J Atheroscler Thromb, 2007; 14: 133-141

17) Hajj Hassan H, Blain S, Boucher B, Denis M, Krimbou L, Genest J: Structural modification of plasma HDL by phospholipids promotes efficient ABCA1-mediated cholesterol release. J Lipid Res, 2005; 46: 1457-1465

18) Iwamoto N, Abe-Dohmae $S$, Ayaori M, Tanaka N, Kusuhara M, Ohsuzu F, Yokoyama S: ATP-binding cassette transporter A1 gene transcription is downregulated by activator protein 2alpha. Doxazosin inhibits activator protein 2alpha and increases high-density lipoprotein biogenesis independent of alpha1-adrenoceptor blockade. Circ Res, 2007; 101: 156-165

19) Dugi KA, Amar MJ, Haudenschild CC, Shamburek RD, Bensadoun A, Hoyt RF, Jr., Fruchart-Najib J, Madj Z, Brewer HB, Jr., Santamarina-Fojo S: In vivo evidence for both lipolytic and nonlipolytic function of hepatic lipase in the metabolism of HDL. Arterioscler Thromb Vasc Biol, 2000; 20: 793-800

20) Vogelstein B, Lane D, Levine AJ: Surfing the p53 network. Nature, 2000; 408: 307-310

21) Tanigawa H, Billheimer JT, Tohyama J, Zhang Y, Rothblat G, Rader DJ: Expression of cholesteryl ester transfer protein in mice promotes macrophage reverse cholesterol transport. Circulation, 2007; 116: 1267-1273

22) Uto-Kondo H, Ayaori M, Ogura M, Nakaya K, Ito M, Suzuki A, Takiguchi S, Yakushiji E, Terao Y, Ozasa H, Hisada T, Sasaki M, Ohsuzu F, Ikewaki K: Coffee con- 
sumption enhances high-density lipoprotein-mediated cholesterol efflux in macrophages. Circ Res, 2010; 106: 779-787

23) Nakaya K, Ayaori M, Uto-Kondo H, Hisada T, Ogura M, Yakushiji E, Takiguchi S, Terao Y, Ozasa H, Sasaki M, Komatsu T, Ohsuzu F, Ikewaki K: Cilostazol enhances macrophage reverse cholesterol transport in vitro and in vivo. Atherosclerosis, 2010; 213: 135-141

24) Bryan J, Aguilar-Bryan L: Sulfonylurea receptors: ABC transporters that regulate ATP-sensitive $\mathrm{K}(+)$ channels. Biochim Biophys Acta, 1999; 1461: 285-303

25) Sheppard DN, Welsh MJ: Effect of ATP-sensitive K+ channel regulators on cystic fibrosis transmembrane conductance regulator chloride currents. J Gen Physiol, 1992; 100: $573-591$

26) Golstein PE, Boom A, van Geffel J, Jacobs P, Masereel B, Beauwens R: P-glycoprotein inhibition by glibenclamide and related compounds. Pflugers Arch, 1999; 437: 652-660

27) Kis E, Ioja E, Nagy T, Szente L, Heredi-Szabo K, Krajcsi P: Effect of membrane cholesterol on BSEP/Bsep activity: species specificity studies for substrates and inhibitors. Drug Metab Dispos, 2009; 37: 1878-1886

28) Sheppard DN, Robinson KA: Mechanism of glibenclamide inhibition of cystic fibrosis transmembrane conductance regulator $\mathrm{Cl}$ - channels expressed in a murine cell line. J Physiol, 1997; 503 (Pt 2): 333-346

29) Fitzgerald ML, Morris AL, Chroni A, Mendez AJ, Zannis VI, Freeman MW: ABCA1 and amphipathic apolipoproteins form high-affinity molecular complexes required for cholesterol efflux. J Lipid Res, 2004; 45: 287-294

30) Kobayashi A, Takanezawa $Y$, Hirata T, Shimizu Y, Misasa K, Kioka N, Arai H, Ueda K, Matsuo M: Efflux of sphingomyelin, cholesterol, and phosphatidylcholine by ABCG1. J Lipid Res, 2006; 47: 1791-1802

31) Wittenburg H, Carey MC: Biliary cholesterol secretion by the twinned sterol half-transporters ABCG5 and ABCG8. J Clin Invest, 2002; 110: 605-609

32) Ohgami N, Kuniyasu A, Furukawa K, Miyazaki A, Hakamata $\mathrm{H}$, Horiuchi S, Nakayama H: Glibenclamide acts as an inhibitor of acyl-CoA:cholesterol acyltransferase enzyme. Biochem Biophys Res Commun, 2000; 277: $417-422$

33) Hakamata H, Miyazaki A, Sakai M, Suginohara Y, Sakamoto Y, Horiuchi S: Species difference in cholesteryl ester cycle and HDL-induced cholesterol efflux from macrophage foam cells. Arterioscler Thromb, 1994; 14: 1860-1865

34) Bernard DW, Rodriguez A, Rothblat GH, Glick JM: Influence of high density lipoprotein on esterified cholesterol stores in macrophages and hepatoma cells. Arteriosclerosis, 1990; 10: 135-144

35) Wu CA, Tsujita M, Hayashi M, Yokoyama S: Probucol inactivates $\mathrm{ABCA1}$ in the plasma membrane with respect to its mediation of apolipoprotein binding and high density lipoprotein assembly and to its proteolytic degradation. J Biol Chem, 2004; 279: 30168-30174

36) Hirano K, Ikegami C, Tsujii K, Zhang Z, Matsuura F, Nakagawa-Toyama Y, Koseki M, Masuda D, Maruyama T, Shimomura I, Ueda Y, Yamashita S: Probucol enhances the expression of human hepatic scavenger receptor class B type I, possibly through a species-specific mechanism. Arterioscler Thromb Vasc Biol, 2005; 25: 2422-2427

37) Nofer JR, Remaley AT, Feuerborn R, Wolinnska I, Engel T, von Eckardstein A, Assmann G: Apolipoprotein A-I activates Cdc42 signaling through the ABCA1 transporter. J Lipid Res, 2006; 47: 794-803

38) Remedi MS, Nichols CG: Chronic antidiabetic sulfonylureas in vivo: reversible effects on mouse pancreatic betacells. PLoS Med, 2008; 5: e206.

39) Wang X, Collins HL, Ranalletta M, Fuki IV, Billheimer JT, Rothblat GH, Tall AR, Rader DJ: Macrophage ABCA1 and ABCG1, but not SR-BI, promote macrophage reverse cholesterol transport in vivo. J Clin Invest, 2007; 117: 2216-2224

40) Zhang Y, Da Silva JR, Reilly M, Billheimer JT, Rothblat $\mathrm{GH}$, and Rader DJ: Hepatic expression of scavenger receptor class B type I (SR-BI) is a positive regulator of macrophage reverse cholesterol transport in vivo. J Clin Invest, 2005; 115: 2870-2874 


\section{On-line Supplement}

\section{Supplemental Methods}

\section{Construction of Luciferase Reporter Plasmids}

Luciferase reporter plasmids (pGL3 Basic; Promega, Madison, WI) containing the human ABCA1 promoter region spanning -940 to $+110 \mathrm{bp}$ (hABCA1 $-940+110)$, the human ABCG1 promoter A spanning -1104 to $+37 \mathrm{bp}$ (located upstream of exon 1 , hABCG1A - 1104+37), and promoter B spanning -1180 to +144 bp (located upstream of exon 5, hABCG1B $-1180+144)$ were generated as previously reported ${ }^{1-4)}$. Liver $X$ receptor-responsive elements (LXRE), direct repeat spaced by four nucleotides, were present in hABCA1 $-940+110$ and hABCG1A $1104+37$, but not in hABCG1B $-1180+144$, as previously reported $^{2,4)}$.

\section{DNA Transfection and Luciferase Assays}

RAW264.7 cells cultured in 24-well plates were transfected with $500 \mathrm{ng}$ luciferase reporter plasmids and $12.5 \mathrm{ng}$ phRL-TK (Promega) per well using Lipofectamine LTX reagent (Invitrogen, Carlsbad, CA) according to the manufacturer's instructions. Ten hours after transfection, the media were replaced with DMEM containing glibenclamide, glimepiride (10 or $100 \mu \mathrm{mol} / \mathrm{L}$ ) or the vehicle and incubated for an additional $24 \mathrm{~h}$. Luciferase assays were performed as previously described ${ }^{2,3)}$.

\section{Endogenous LCAT Assays}

Plasma LCAT cholesterol esterification rate (CER) was determined using a modification of the Stokke and Norum procedure ${ }^{5-7)}$. Briefly, a pooled plasma sample $(200 \mu \mathrm{L})$ was incubated with BSA solution containing $3 \times 10^{6} \mathrm{dpm}$ of ${ }^{3} \mathrm{H}$-cholesterol on ice overnight. The samples were diluted to $1200 \mu \mathrm{L}$ with $0.2 \mathrm{M}$ phosphate buffer $(\mathrm{pH} 7.4)$ and divided into four aliquots. Three aliquots were incubated at $37^{\circ} \mathrm{C}$ for $60 \mathrm{~min}$ while one aliquot was maintained at
$4{ }^{\circ} \mathrm{C}$ as a control. Lipid was extracted by the Bligh/ Dyer method and free cholesterol (FC) and cholesteryl ester (CE) were separated by thin layer chromatography. The CE and FC spots were cut off and the radioactivity was measured. Endogenous LCAT activity was expressed as $\mathrm{CE} /(\mathrm{CE}+\mathrm{FC}) \times 100(\%)$.

\section{References}

1) Uehara $Y$, Miura $S$, von Eckardstein $A$, Abe $S$, Fujii $A$, Matsuo Y, Rust S, Lorkowski S, Assmann G, Yamada T, Saku K: Unsaturated fatty acids suppress the expression of the ATP-binding cassette transporter G1 (ABCG1) and $A B C A 1$ genes via an LXR/RXR responsive element. Atherosclerosis, 2007; 191: 11-21

2) Ayaori M, Sawada S, Yonemura A, Iwamoto N, Ogura M, Tanaka N, Nakaya K, Kusuhara M, Nakamura H, Ohsuzu F: Glucocorticoid receptor regulates ATP-binding cassette transporter-A1 expression and apolipoprotein-mediated cholesterol efflux from macrophages. Arterioscler Thromb Vasc Biol, 2006; 26: 163-168

3) Nakaya K, Ayaori M, Hisada T, Sawada S, Tanaka N, Iwamoto N, Ogura M, Yakushiji E, Kusuhara M, Nakamura $\mathrm{H}$, Ohsuzu F: Telmisartan enhances cholesterol efflux from THP-1 macrophages by activating PPARgamma. J Atheroscler Thromb, 2007; 14: 133-141

4) Sabol SL, Brewer HB, Jr., Santamarina-Fojo S: The human ABCG1 gene: identification of LXR response elements that modulate expression in macrophages and liver. J Lipid Res, 2005; 46: 2151-2167

5) Stokke KT, Norum KR: Determination of lecithin: cholesterol acyltransfer in human blood plasma. Scand J Clin Lab Invest, 1971; 27: 21-27

6) Zhao Y, Thorngate FE, Weisgraber KH, Williams DL, Parks JS: Apolipoprotein E is the major physiological activator of lecithin-cholesterol acyltransferase (LCAT) on apolipoprotein B lipoproteins. Biochemistry, 2005; 44: 1013-1025

7) Tanigawa H, Billheimer JT, Tohyama J, Fuki IV, Ng DS, Rothblat GH, Rader DJ: Lecithin: cholesterol acyltransferase expression has minimal effects on macrophage reverse cholesterol transport in vivo. Circulation, 2009; 120: $160-169$ 
A

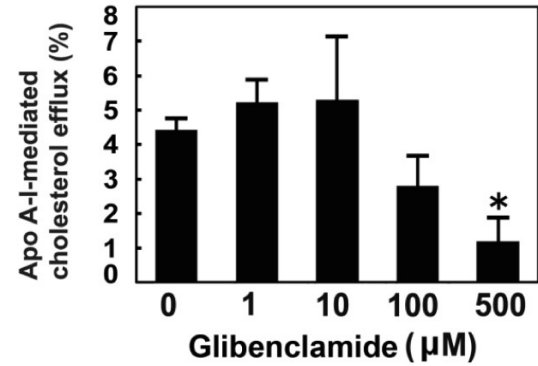

B

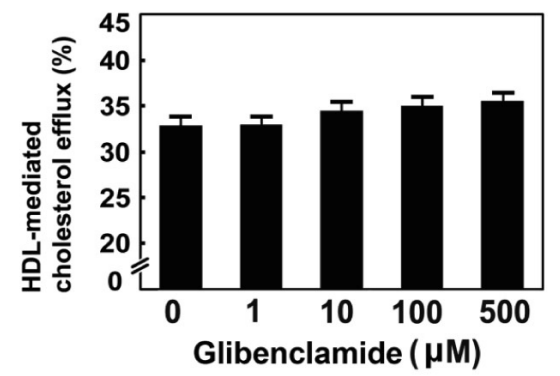

C

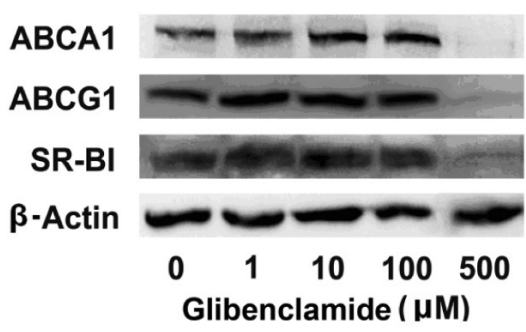

D

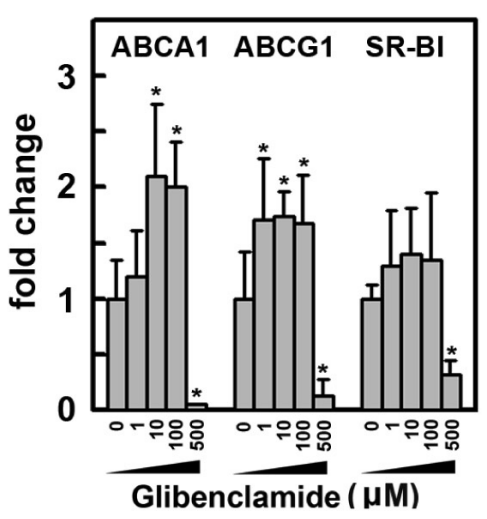

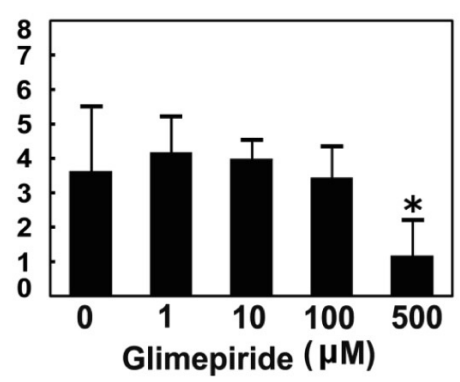
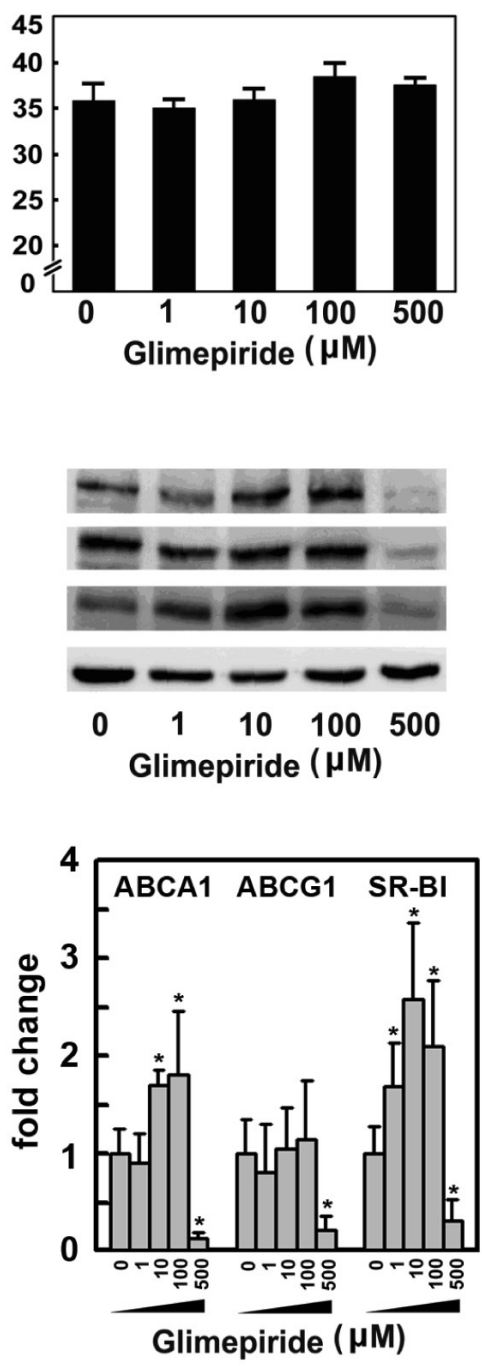

Supplemental Fig. 1. Effects of SUAs on apoA-I - and HDL-mediated cholesterol efflux and ABCA1, ABCG1 and SR-BI protein expressions in THP-1 macrophages

Seventy-two hours after treating THP-1 cells with $320 \mathrm{nM}$ PMA, the cells were labeled with ${ }^{3} \mathrm{H}$-cholesterol and the indicated doses of SUAs or the vehicle were added to the cultures, which were then incubated in the presence of $10 \mu \mathrm{g} / \mathrm{mL}$ human apoA-I (A) or $50 \mu \mathrm{g} / \mathrm{mL} \mathrm{HDL}$ (B) for $24 \mathrm{~h}$. Cholesterol efflux was determined as described in Methods. The results for 3 samples are presented as the mean \pm SD. C, THP-1 macrophages were treated with the indicated concentrations of SUAs or the vehicle for $24 \mathrm{~h}$. The cells were lysed and Western blot analysis was performed as described in Methods. The results are from 3 separately performed experiments that yielded similar results. D, Protein levels were quantified as described in Methods. The results are presented as the mean \pm SD. ${ }^{*} P<0.05$ vs. control. 

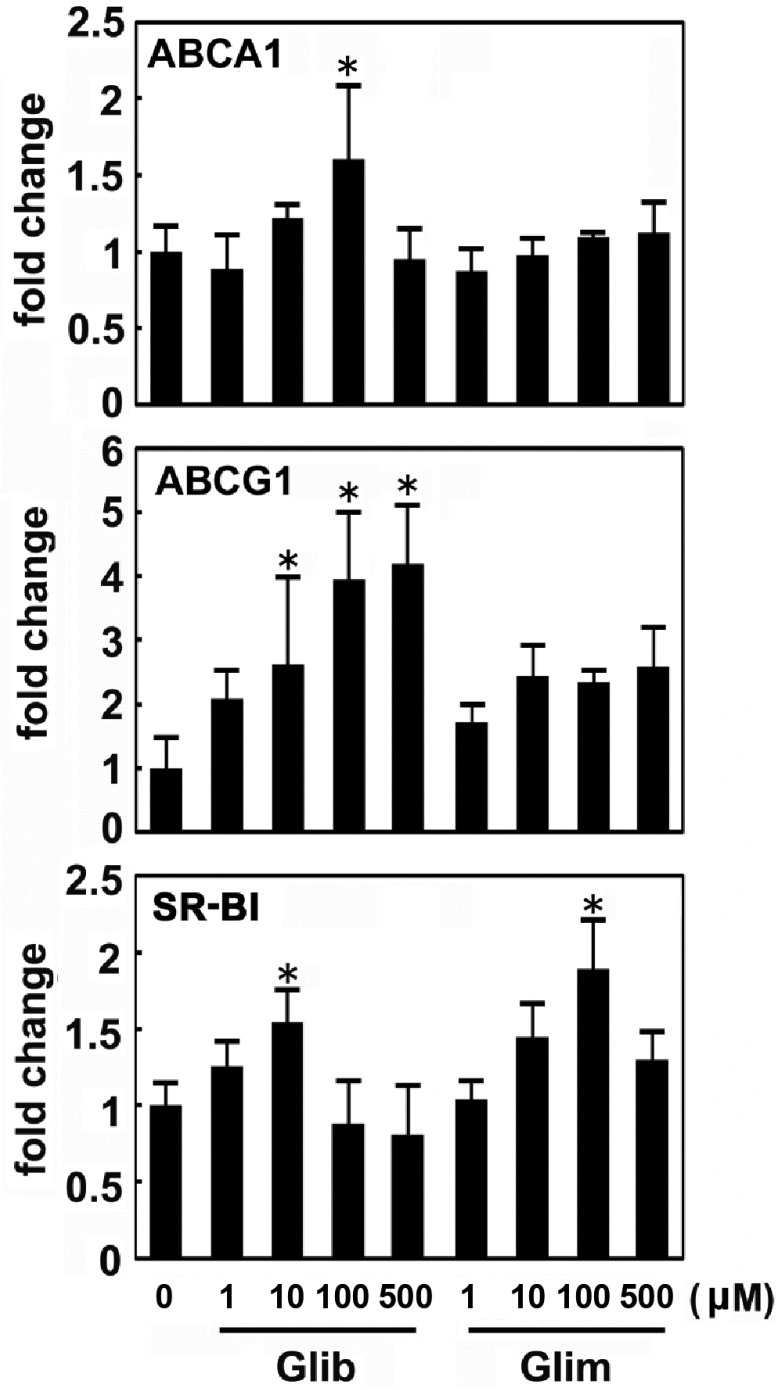

Supplemental Fig. 2. Effects of SUAs on ABCA1, ABCG1 and SR-BI mRNA levels in THP-1 macrophages

Seventy-two hours after treating THP-1 cells with $320 \mathrm{nM}$ of PMA, the cells were treated with the indicated concentrations of glibenclamide (Glib), glimepiride (Glim) or the vehicle for $24 \mathrm{~h}$. RNA extraction and real-time quantitative RT-PCR were performed as described in Methods. The mRNA levels of each gene were standardized for GAPDH levels. The results from 3 replicate wells are expressed relative to the controls and presented as the mean \pm SD. ${ }^{*} P<0.05$ vs. control.

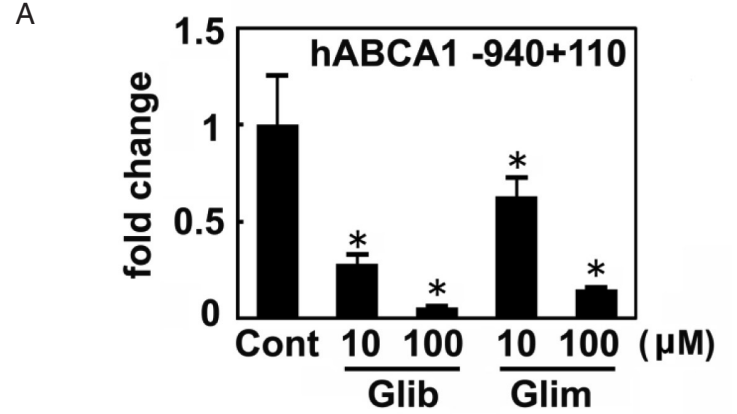

B
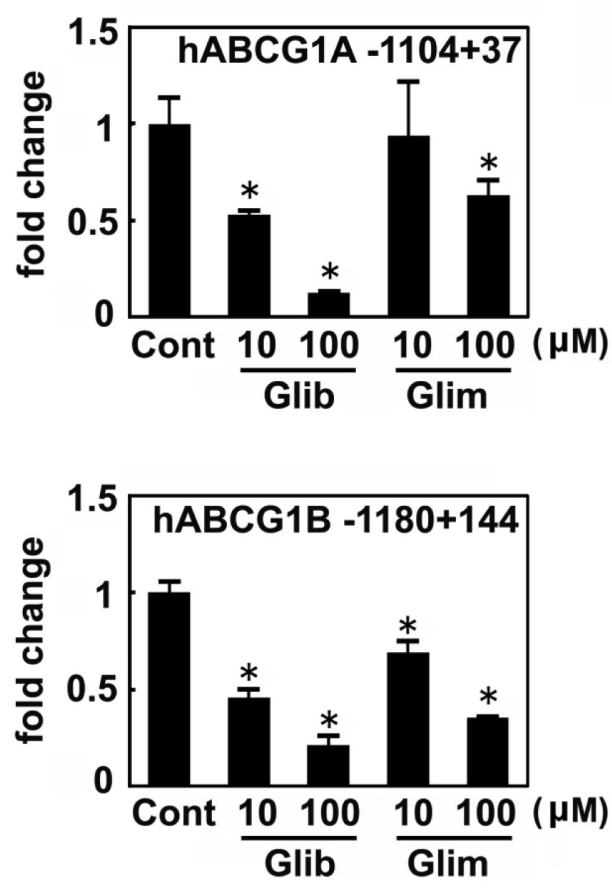

Supplemental Fig. 3. Effects of SUAs on ABCA1 and ABCG1 promoter activity

After transfection with hABCA1 -940+110 (A), hABCG1A $1104+37$ (B), or hABCG1B - 1180+144 (C), RAW264.7 cells were treated with the indicated concentrations of glibenclamide (Glib), glimepiride (Glim) or the vehicle (Cont) as described in Supplemental Methods. Twenty-four hours after the treatments, the cells were lysed and a luciferase assay performed. The results from 3 separately performed experiments are expressed relative to the controls and presented as the mean \pm SD. ${ }^{*} P<0.05$ vs. control. 
Supplemental Table 1. Summary of the effects of glibenclamide $(500 \mu \mathrm{M})$ on mRNA/protein expressions of ABCA1/G1/SR-BI in macrophages or other cell lines and apoA-I/HDL-mediated cholesterol efflux

\begin{tabular}{|c|c|c|c|c|c|c|}
\hline & & mRNA & protein & & A-I efflux & HDL efflux \\
\hline \multirow[t]{3}{*}{ ABCA 1} & RAW & $\downarrow$ & $\downarrow$ & RAW & $\downarrow$ & $\uparrow$ \\
\hline & THP-1 & $\rightarrow$ & $\downarrow$ & THP-1 & $\downarrow$ & $\rightarrow$ \\
\hline & exogenous expression & - & $\rightarrow$ & & & \\
\hline \multirow[t]{3}{*}{ ABCG1 } & RAW & $\rightarrow$ & $\uparrow$ & & & \\
\hline & THP-1 & $\uparrow$ & $\downarrow$ & & & \\
\hline & exogenous expression & - & $\downarrow$ & & & \\
\hline \multirow[t]{3}{*}{ SR-BI } & RAW & $\rightarrow$ & $\rightarrow$ & & & \\
\hline & THP-1 & $\rightarrow$ & $\downarrow$ & & & \\
\hline & exogenous expression & - & $\downarrow$ & & & \\
\hline
\end{tabular}

Supplemental Table 2. Effects of SUAs on body weight, blood glucose and lecithin cholesterol acyltransferase activity in mice

\begin{tabular}{lcccccccc}
\hline & \multicolumn{4}{c}{ Pre } & & & \multicolumn{3}{c}{ Post } \\
\cline { 2 - 3 } & control & glibenclamide & glimepiride & & control & glibenclamide & glimepiride \\
\hline BW & $22.3 \pm 1.8$ & $22.8 \pm 0.8$ & $23.3 \pm 0.4$ & & $22.2 \pm 1.3$ & $22.1 \pm 0.4$ & $23.2 \pm 0.2$ \\
Blood glucose $(\mathrm{mg} / \mathrm{dl})$ & $176.3 \pm 24.8$ & $179.3 \pm 28.5$ & $187.2 \pm 39.6$ & & $173.8 \pm 22.0$ & $170.4 \pm 19.2$ & $159.0 \pm 35.9$ \\
LCAT actibity (\%) & - & - & - & & $19.0 \pm 0.8$ & $17.5 \pm 1.2$ & $19.7 \pm 3.6$ \\
\hline
\end{tabular}

BW, body weight; LCAT, lecithin cholesterol acyltransferase. 